\title{
A randomized controlled pilot trial of a smoking cessation intervention for US women living with HIV: telephone-based video call vs voice call
}

This article was published in the following Dove Press journal: International Journal of Women's Health

\author{
Sun S Kim' \\ Sabreen Darwish' \\ Sang A Lee' \\ Courtenay Sprague ${ }^{1-3}$ \\ Rosanna F DeMarco' \\ 'Department of Nursing, College \\ of Nursing and Health Sciences, \\ University of Massachusetts Boston, \\ Boston, MA, USA; ${ }^{2}$ Department \\ of Conflict Resolution, Global \\ Governance and Human Security, John \\ W. McCormack Graduate School of \\ Policy and Global Studies, Boston, MA, \\ USA; ${ }^{3}$ Wits Reproductive Health and \\ HIV Institute, School of Public Health, \\ Faculty of Health Sciences, University \\ of the Witwatersrand, Johannesburg, \\ South Africa
}

Background: People living with HIV smoke at a rate three times that of the general population. This randomized controlled pilot trial tested the feasibility and acceptability of a video-call smoking cessation intervention in women living with HIV and its preliminary efficacy compared with a voice-call smoking cessation intervention. The study focused on women due to a paucity of studies among this population, and women are less likely than men to quit smoking when provided with conventional treatment.

Methods: Participants in both arms received an HIV-tailored smoking cessation intervention comprising eight 30-minute weekly counseling sessions in conjunction with active nicotine patches for 8 weeks. The only difference between the two arms was the delivery mode of the intervention: via either telephone-based video or voice call. Survival analysis and a Cox proportional hazard regression model were performed to identify factors predicting 6-month prolonged abstinence from smoking.

Results: A video-call intervention was almost $30 \%$ less feasible than a voice-call intervention because women in their $50 \mathrm{~s}$ and $60 \mathrm{~s}$ or poorer women living in some southern states did not have access to video-call equipment. However, those who received the video-call intervention were more likely to complete the study than those who had the voice-call intervention. There was no difference in the acceptability of the two interventions. A survival analysis revealed that those in the video arm were significantly more likely to maintain smoking abstinence over the 6 -month follow-up period than those in the voice arm $\left(\log \operatorname{rank} \chi^{2}=4.02, P<0.05\right)$.

Conclusion: Although a video-call intervention is less feasible than a voice-call intervention, the former seems to outperform the latter in achieving long-term smoking abstinence for women living with HIV, which may offer an advantage over establishing therapeutic alliance and visually monitoring their adherence to nicotine patches.

Clinical trial registration: ClinicalTrials.gov NCT02898597.

Keywords: HIV, women, smoking cessation intervention, video call

\section{Introduction}

People living with HIV (PLWH) smoke cigarettes at a rate three times that of the general population: $40 \%-80 \%$ compared to $19 \%$. ${ }^{1,2}$ One large cohort study estimated that $24 \%$ of deaths in PLWH with antiretroviral therapy (ART) are attributable to tobacco use. ${ }^{3}$ Smoking cessation is therefore crucial to reduce the high mortality rate in this population and to improve their quality of life. A systematic review of smoking cessation studies reported that PLWH prefer telephone to in-person counseling. ${ }^{4}$ Their preference for telephone-based interventions might be related to actual and perceived barriers to accessing health care systems, including lack of transportation to the tobacco
Correspondence: Sun S Kim Department of Nursing, College of Nursing and Health Sciences, University of Massachusetts Boston, 100 William T Morrissey Blvd, Boston, MA, USA Email sun.kim@umb.edu 
treatment center, schedule conflict, housing instability, and social stigma. ${ }^{5,6}$ However, the rates of abstinence achieved by PLWH who received telephone counseling were relatively low at $6 \%-16 \%,{ }^{5-7}$ compared to the rates of in-person counseling, ranging from $15 \%$ to $30 \% .^{8-10}$

Smoking cessation studies found that PLWH who were married, older, employed, or had a low level of nicotine dependence or no mood disturbance, such as depression and anxiety, were more likely to quit smoking than their respective counterparts. ${ }^{11-13}$ These predictors of smoking cessation were similar to those found in the general US population. On the other hand, PLWH-specific cessation predictors included the use of ART and higher CD4 cell counts, although results have been inconsistent. ${ }^{11-13}$

Gender differences in smoking behavior have also been reported in the general US population: women were found to be less likely to be heavy smokers and less nicotine dependent than men. ${ }^{14,15}$ Nevertheless, women had significantly lower confidence in quitting smoking and lower success rates than men, especially when treated with nicotine replacement therapy (NRT) alone or in combination with brief counseling. ${ }^{16-22}$ A meta-analysis reported that women would require more intensive counseling support for smoking cessation than their male counterparts. ${ }^{23}$ Overall, there is a dearth of smoking cessation studies focused on women living with HIV. Compared to men, women living with HIV are more likely to face significant impediments in accessing health care services and treatments that they need to cease smoking, including socioeconomic and structural barriers such as childcare needs and intimate partner violence. ${ }^{24,25}$

Video-call smoking cessation counseling offers a viable alternative to traditional telephone counseling (eg a quit-line service) for women smokers living with HIV because face-toface interaction facilitates the establishment of a therapeutic alliance with participants. Moreover, therapists can monitor adherence to nicotine patches during the video-call session. Telemedicine, including counseling, has grown rapidly for various health conditions that include depression, cancer, and diabetes, and also provides genetic counseling. ${ }^{26-30} \mathrm{Clini-}$ cians are generally satisfied with the telemedicine experience and there seems to be no difference in treatment outcomes between telemedicine and an office visit. ${ }^{31-34}$ Until a few years ago, telemedicine had been delivered with sophisticated teleconferencing equipment. Recently, however, researchers tested a more accessible medium using webcams and standard Internet connectivity, which demonstrated similar satisfactory transmissions and acceptability. ${ }^{32,35-37}$ Furthermore, the advent of video call applications (apps) by smartphone use, such as Skype, Messenger, IMO, Google Duo, and Tango, makes videoconferencing easier than ever before. ${ }^{38}$ Smokers can have counseling sessions in a virtual office via a video call without having to leave the comfort and security of their home.

Four studies were retrieved from an intensive literature search for any video-call smoking cessation intervention studies, and only one of them was done with PLWH. ${ }^{35,38-40}$ The first study, conducted in Canada, concluded that videocall counseling (Telehealth) was as effective as in-person counseling (26\% vs 28\%). ${ }^{35}$ The remaining three studies were conducted in the US: one for general smokers in a primary care clinic, one for Korean American women, and one group therapy for PLWH. ${ }^{38-40}$ The first two found no differences in videoconferencing and telephone counseling cessation interventions and both were equally effective. ${ }^{38,39}$ The third study was not a randomized controlled trial and provided the same intensive video-group-based smoking cessation for all PLWH. ${ }^{40}$ At the 3-month follow-up of the study, 14\% $(n=3)$ reported biochemically confirmed 7-day point-prevalence abstinence. All studies underscored the advantages of a videoconferencing intervention in reaching smokers who were living in resource-limited communities.

To the best of our knowledge, there is no single study that compared the efficacy of an HIV-tailored smoking cessation intervention between the two delivery modes: video call vs voice call. The purpose of this study was twofold: 1) to test the feasibility and acceptability of a video-call smoking cessation intervention tailored to the specific needs of women living with HIV and 2) to estimate a preliminary effect size of the video-call intervention compared to the voice-call cessation intervention. It was hypothesized that the videocall smoking cessation intervention would be as feasible and acceptable as the voice-call intervention for women living with HIV, and that those who received the video-call intervention would be more likely to maintain smoking abstinence over a 6-month follow-up period compared with those who received the voice-call intervention.

\section{Research method Design overview}

The study was a two-arm randomized controlled pilot trial of a smoking cessation intervention for women living with HIV. Participants in both arms received eight weekly counseling sessions for smoking cessation along with open-label nicotine patches, also for 8 weeks. The content of the counseling sessions was adapted for the unique needs of women living with HIV. Participants in both arms received the same 
HIV-tailored smoking cessation intervention irrespective of group allocation, and the only difference between the two arms was the delivery mode of the intervention: telephonebased video call vs telephone-based voice call. The study was approved by the University of Massachusetts Boston Institutional Review Board.

\section{Participants}

Inclusion criteria were based on self-reports and included: 1) women; 2) English-speaking ability; 3) HIV-positive serostatus and CD4 cell count and viral load; 4) 18-75 years old; 5) smokers reporting at least five cigarettes a day for the past 6 months; 6) access to video calling, via smartphone; 7) willingness to set a quit date within 4 weeks from the first counseling session; and 8) the usage of an approved form of birth control (eg oral medications, condoms, and intrauterine devices) during the study period. Individuals were excluded if they: 1) were not able to speak English; 2) were pregnant or lactating; 3) self-reported an active skin disease; serious alcohol use ( $\geq 26$ on the Alcohol Use Disorders Identification Test); ${ }^{41} 4$ ) a history of serious mental illness (psychotic and bipolar disorders); or 5) illegal substance use, excluding marijuana. These exclusion criteria were established because participants were remotely recruited without direct physical interactions, which made it difficult for the research team to intervene promptly if there were any medical emergencies.

\section{Recruitment procedures}

Women living with HIV were recruited across the nation utilizing professional networks of health care providers who were working with PLWH and study adverts placed on the free website, Craigslist. Callers were first screened via a brief telephone interview, and then, those who were determined to be eligible were informed of the study purpose and procedures. Women who were willing to participate in the study were asked to provide their contact information. They then received an envelope enclosed with a cover letter, informed consent form, baseline research questionnaire, smoking log sheet, and self-addressed stamped envelope for return mail. The research team validated whether the consent form was signed and the questionnaire duly completed without missing information. The research team conducted subsequent telephone interviews for additional information and clarification, as needed.

HIV serostatus was confirmed by asking participants to provide their CD4 cell count and viral load at the time of the screening interview. Some women sent a copy of their most recent blood work if they were not able to provide their CD4 cell counts and viral loads during the screening interview. Participants were randomized to either the video arm for videoconferencing or the voice arm for the traditional telephone counseling after the completion of the consent form and baseline research questionnaire. Two-block randomization was implemented using a computer-generated random number. Participants and research team members did not have any prior knowledge of group allocation until it was determined by a random number along with the corresponding group that was enclosed in a sealed envelope. Participants in the video arm were all instructed to install IMO (a video call app), unless they had previously been using a different app.

\section{Interventions}

Counseling contents were primarily drawn from a cognitive behavioral therapy foundation, which is guided by Bandura's Social Cognitive Theory. ${ }^{42}$ Problem solving skills and techniques for resisting smoking temptation were emphasized. ${ }^{43}$ The intervention was composed of eight weekly individualized counseling sessions of smoking cessation and NRT for 8 weeks. Each of the counseling sessions would last 10-30 minutes. During the first counseling session, a quit day was set by discussion between the therapist and participant. The participant was strongly encouraged to choose the day between the third and fifth sessions so that she could have at least three to four counseling sessions before and after the planned quit day. The reason for choosing this timeline for quitting smoking was to help participants prepare for the day and manage symptoms of nicotine withdrawal and side effects of nicotine patches. However, several women were not able to choose the quit day during the first counseling session and selected the day at either the second or the third session. The therapist devoted a substantial amount of time during the first three counseling sessions explicating the serious detrimental combined effects of ART and smoking on the cardiovascular system, in addition to other health risks of smoking that are unique to women in general and women living with HIV in particular. ${ }^{44}$ Post-quit counseling sessions were focused on assessing and managing nicotine withdrawal symptoms with behavioral strategies and side effects of nicotine patches. Further details of the counseling sessions have been previously described. ${ }^{45}$

Participants in both arms received an 8-week supply of nicotine patches by two postage mailings: first 4-week supplies of $21 \mathrm{mg}$, followed by 2-week supplies of both 14 and $7 \mathrm{mg}$. Those who smoke between 5 and 9 cigarettes received a 4-week supply of $14 \mathrm{mg}$ by the first mail and then a 2-week 
supply of both 14 and $7 \mathrm{mg}$ by the second mail. The dosages and length of the patches were based on recommendations made by the US Public Health Service Guidelines. ${ }^{46}$ According to the guidelines, "Clinicians should encourage all patients attempting to quit to use effective medications for tobacco dependence treatment, except where contraindicated" (p 106). ${ }^{46}$

\section{Data collection}

Baseline data were self-administered in paper-and-pencil format, and all follow-up assessments were done with telephone interviews at 1-, 3-, and 6-month post-quit. At baseline, demographic characteristics, such as race and ethnicity, age, marital status, and years of education, were assessed. In addition, the year of HIV diagnosis, the most recent CD4 count and viral load, age at smoking onset, the number of cigarettes smoked per day on average, and any quit attempts within the past year were assessed. All follow-up assessments were done by an individual who was not the therapist, and the person was not fully blind to the group allocation because she had to assist some participants in installing a video call app. A salivary cotinine test was read in a blind condition and consensus was sought among the research team if the first and second readers disagreed. The primary outcomes of the study were feasibility and acceptability of the video-call smoking cessation intervention.

\section{Measures}

\section{Feasibility}

This was assessed in three ways: 1) the feasibility of enrolling women living with HIV into the study was assessed; 2) the feasibility of administering the video-call intervention was done; and 3) the feasibility of retaining participants in a 7-month longitudinal study was assessed.

\section{Acceptability}

Client Satisfaction Questionnaire (CSQ) was used to assess the acceptability of the video-call smoking cessation intervention. ${ }^{47}$ This is an eight-item brief assessment, asking individuals about the quality of the smoking cessation intervention provided to them; the extent that the intervention met their needs; willingness to recommend the intervention to others in need of similar help; and willingness to have the intervention in future if additional services were to be offered. Each item was coded with a 4-point Likert-type scale ranging from 1 (quite dissatisfied) to 4 (very satisfied). The scale had been frequently used for evaluations of diverse health interventions. Cronbach's alpha was 0.75 in the present study.

\section{Smoking abstinence}

Six-month prolonged abstinence was another primary outcome of the study and defined as continuous abstinence, except for the first 2-week grace period. ${ }^{48}$ It was assessed by self-report at each follow-up and with biochemical verification at 3- and 6-month follow-ups. First, participants were asked about whether they had been abstinent or smoking. If abstinent, participants were asked whether there were any lapses or relapse between follow-ups, and if there had been additional relapses after they recovered from the first relapse. If smoking, they were asked how long they had been smoking and how many cigarettes per day they were smoking. Self-reported abstinence was biochemically verified using the NicAlert ${ }^{\circledR}$ Test (Nymox Pharmaceutical Corporation, Hasbrouck Heights, NJ, USA). It is a semi-quantitative measure of cotinine based on a colorimetric immunoassay reaction. Cotinine is the major proximate metabolite of nicotine and has a long half-life of $\sim 15-19$ hours. ${ }^{49}$ The test strip displays seven zones that represent a range of cotinine levels from $0(0-10 \mathrm{ng} / \mathrm{mL})$ to $6(\geq 2,000 \mathrm{ng} / \mathrm{mL})$. Those who yielded results other than 0 (cotinine concentration: 0-10 ng/mL) were all treated as smokers, regardless of their self-reported smoking status. Participants performed the test at home following instructions from research staff who closely monitored the whole testing process via video call.

\section{HIV-related stigma scale}

This scale is a reliable and valid measure, and for which sound psychometric properties have been previously established with a large, diverse sample of people with HIV. ${ }^{50}$ Four factors emerged from an exploratory factor analysis: personalized stigma, disclosure concerns, negative selfimage, and concern with public attitudes toward people with HIV. Extraction of one higher-order factor provided evidence of a single overall construct. Construct validity was also supported by relationships with related constructs: depression, self-esteem, social support, and social conflict in which Pearson correlation coefficients ranged from 0.90 to 0.93 among the four subscales and 0.96 for the 40 -item instrument. ${ }^{50,51}$ In the present study, Cronbach's alphas ranged from 0.76 to 0.89 for the subscales and 0.93 for the total scale.

\section{Fagerström Test for Nicotine Dependence (FTND)}

This scale assesses the intensity of physiological dependence on nicotine and consists of six items. Each answer has a weighted score ranging from 0 to 3 ; two of the items range from 0 to 3 and the remaining from 0 to $1 .^{52}$ The scale score 
is the sum of each item score and can range from 0 to 10 . Cronbach's alpha of the measure ranged from 0.55 to 0.74 in previous studies. ${ }^{53-56}$ Factor analysis of the FTND has yielded inconsistent results between one and two factors. ${ }^{55-59}$ Nonetheless, the FTND has been most widely used as a measure of nicotine dependence, and we also used it in the study. It was suggested that violation of tau-equivalence has been the cause of the low internal reliability. ${ }^{60}$ Cronbach's alpha was 0.56 in the current study.

\section{Self-efficacy scale in quitting smoking}

This scale assesses participants' confidence in avoiding smoking when faced with high risk smoking situations (eg, "when I feel tense or anxious", "when I wake up in the morning") ${ }^{61}$ It has nine items, and each item has a range from 1 ("completely unconfident") to 5 ("completely confident"), and the scale score is the sum of each item score. The scale has sound psychometric properties with high reliability coefficient scores and acceptable factor findings. ${ }^{61,62}$ A Cronbach's alpha of 0.83 was obtained in the present study.

\section{Center for Epidemiologic Studies- Depression (CES-D) scale}

The CES-D scale consists of 20 items and is an adequate screening instrument for clinical depressive disorder in the general population. ${ }^{63}$ Individuals rate how often they have experienced each symptom over the past week on a 4-point (0-3) scale from 0 ("rarely or none of the time") to 3 ("most or all of the time"). A cutoff point of 16 is suggested as the best predictor of clinical depression, and the scale has been known for its sound psychometric properties. ${ }^{64-66}$ A Cronbach's alpha of 0.92 was estimated in the present study.

\section{Generalized Anxiety Disorder 7-items (GAD-7) scale}

Anxiety symptoms were assessed using the seven items of the GAD scale and responses to the items ranged from 0 ("not at all") to 3 ("nearly every day"). Scores of 10 or higher had a sensitivity of $89 \%$ and a specificity of $82 \%$ for GAD compared with the Diagnostic and Statistical Manual of Mental Disorders IV Text Revision (DSM-IV-TR). ${ }^{67}$ A Cronbach's alpha of 0.94 was obtained in the present study.

\section{Minnesota Nicotine Withdrawal Scale (MNWS)}

This scale was initially developed with nine items including craving and later modified to reflect changes made in the DSM-IV criteria for nicotine withdrawal. ${ }^{68}$ People rate the symptoms of nicotine withdrawal as not present $(0)$, slight (1), mild (2), moderate (3), and severe (4), yielding a total score between 0 and 36 . The psychometric properties of the MNWS have been well established. ${ }^{68,69}$ The scale was assessed at each counseling session during the first 4 weeks from the quit day. Cronbach's alphas of 0.89-0.93 were obtained in the present study.

\section{Data analysis}

Data entry was independently double-checked by two members of the research team and analyzed using STATA 15 (StataCorp LP, College Station, TX, USA). Descriptive statistics of demographics and study variables and differences between the two intervention arms were performed using Mann-Whitney $U$-tests or independent $t$-tests for continuous variables and the $\chi^{2}$ tests for categorical variables. The feasibility of enrollment was assessed by estimating percentage of the women who could not participate in the study because of no access to video-call equipment among those who were otherwise eligible. The feasibility of intervention delivery was done by comparing the rate of completion of the eight weekly sessions between the video and voice arms. The feasibility of retention was assessed by comparing the rate of completion of the 7-month longitudinal study between the two arms. The acceptability of the intervention delivered was analyzed by comparing the average scores of the CSQ between the two arms. Survival analysis was conducted to examine the relationship between the two arms, and 6-month prolonged abstinence using the Kaplan-Meier survival plot and Cox proportional hazard model for possible covariates such as nicotine dependence and self-efficacy in resisting smoking temptation. Those who were missing at follow-ups were all treated as smokers based on the intention-to-treat analytic strategy.

\section{Power and sample size}

The study was conducted to establish a preliminary effect size of a video-call smoking cessation intervention compared to a telephone counseling cessation intervention. For pilot studies, it was suggested that 24 subjects per arm generally yields a near accurate estimate of an effect size. ${ }^{70}$ The initial sample sizes were 25 and 24 for the video and voice arms, respectively.

\section{Results}

Most participants were recruited from two states: Massachusetts and New York. The majority were referred by their health care workers who informed them of the study 
purpose and supplied them with the contact information of the research team. The health care workers were identified from the professional networks of two authors (Drs DeMarco and Sprague) who have been studying PLWH for many years. Three women were recruited from the free website www. craigslist.com. Recruitment took place over 14 months from July 2016 through September 2017. Demographic data of the participants are shown in Table 1 . The women were 51 years of age on average (range: $25-65$ ) at the time of the study and had been living with HIV for $\sim 18$ years (range: 2-32, Table 1). The average age of smoking onset was 18 years (range: 11-40). Nearly three-fourths of the participants selfidentified as black (or African American).
Feasibility

Feasibility of enrollment

Of 101 people who made the first contact via either calls or e-mails, 94 (93.1\%) were successfully screened and $74(78.7 \%, 74 / 94)$ were found to be eligible. However, 18 women $(24.3 \%, 18 / 74)$ were further excluded because they did not have access to video-call equipment (Figure 1). The majority of the women who were excluded were from southern states, which tend to have higher poverty rates than other US states. For example, five out of six women (83.3\%) who called from Birmingham, Alabama, were excluded. Seven eligible women declined participation, with three stating that they were too busy and four not specifying a

Table I Baseline characteristics of the study sample

\begin{tabular}{|c|c|c|c|}
\hline \multirow[t]{2}{*}{ Variables } & \multirow{2}{*}{$\begin{array}{l}\text { Voice arm } \\
(n=2 I) \\
n(\%) / \text { mean } \pm S^{a}\end{array}$} & \multirow{2}{*}{$\begin{array}{l}\text { Video arm } \\
(n=2 I) \\
n(\%) / \text { mean } \pm \text { SD }\end{array}$} & \multirow{2}{*}{$\begin{array}{l}\text { Total } \\
(\mathrm{n}=42) \\
\mathrm{n}(\%) / \text { mean } \pm \mathrm{SD}\end{array}$} \\
\hline & & & \\
\hline Age & $52.52 \pm 5.79$ & $49.71 \pm 9.06$ & $51.12 \pm 7.65$ \\
\hline \multicolumn{4}{|l|}{ Ethnicity } \\
\hline Hispanic & $7(33.33)$ & $5(23.8 I)$ & $12(28.57)$ \\
\hline Non-Hispanic & $14(66.67)$ & $16(76.19)$ & $30(71.43)$ \\
\hline \multicolumn{4}{|l|}{ Race } \\
\hline Black & $16(76.19)$ & I5 (7I.43) & $3 I(73.8 I)$ \\
\hline White & $2(9.52)$ & $2(9.52)$ & $4(9.52)$ \\
\hline All others (eg, multiracial) & $3(14.29)$ & $4(19.05)$ & $7(16.67)$ \\
\hline \multicolumn{4}{|l|}{ Education $^{\mathrm{b}}$} \\
\hline$<12$ years & $9(42.86)$ & $4(19.05)$ & $13(30.95)$ \\
\hline$=12$ years & $8(38.10)$ & $16(76.19)$ & $24(57.14)$ \\
\hline$>12$ years & $4(19.05)$ & I (4.76) & $5(11.90)$ \\
\hline \multicolumn{4}{|l|}{ Marital status } \\
\hline Married or living with partner & $7(33.33)$ & $6(28.57)$ & $13(30.95)$ \\
\hline All others & $14(66.67)$ & I5 (7I.43) & $29(69.05)$ \\
\hline \multicolumn{4}{|l|}{ Employment } \\
\hline Employed & $6(71.43)$ & $9(42.86)$ & $33(80.50)$ \\
\hline Unemployed & I5 (28.57) & $12(57.14)$ & $8(19.50)$ \\
\hline Years after HIV diagnosis & $18.05 \pm 7.95$ & $19.14 \pm 7.53$ & $18.60 \pm 7.67$ \\
\hline CD4 count ${ }^{\mathrm{b}}$ & $865.90 \pm 379.76$ & $624.76 \pm 238.33$ & $742.39 \pm 334.36$ \\
\hline \multicolumn{4}{|l|}{ Viral load } \\
\hline Undetectable & $14(70.00)$ & $17(80.95)$ & $31(75.6 I)$ \\
\hline Detectable & $6(30.00)$ & $4(19.05)$ & $10(24.39)$ \\
\hline Perceived HIV-related stigma & $49.90 \pm 15.34$ & $52.19 \pm|2.2|$ & $51.05 \pm 13.74$ \\
\hline Age at smoking onset & $19.11 \pm 6.88$ & $|7.1| \pm 6.8 \mid$ & $18.08 \pm 6.82$ \\
\hline Years of smoking & $34.00 \pm 7.58$ & $32.32 \pm 12.01$ & $33.14 \pm 10.00$ \\
\hline Number of cigarettes per day & $16.07 \pm 7.84$ & $12.38 \pm 4.93$ & $14.23 \pm 6.73$ \\
\hline Nicotine dependence ${ }^{c}$ & $6.10 \pm 1.67$ & $5.05 \pm 1.88$ & $5.57 \pm 1.84$ \\
\hline Self-efficacy in quitting smoking & $23.33 \pm 7.21$ & $24.48 \pm 9.39$ & $23.90 \pm 8.29$ \\
\hline Stigma about smoking & $2.86 \pm 1.90$ & $2.95 \pm 1.50$ & $2.90 \pm 1.69$ \\
\hline \multicolumn{4}{|c|}{ Current use of other substances } \\
\hline Alcohol $(=\text { yes })^{c}$ & $10(47.62)$ & $4(19.05)$ & $13(33.33)$ \\
\hline Marijuana and others (= yes) & II (52.38) & $7(33.33)$ & $18(42.86)$ \\
\hline Depressive symptoms & $20.33 \pm 14.73$ & $18.48 \pm 12.58$ & $19.40 \pm 13.56$ \\
\hline Anxiety symptoms & $7.90 \pm 7.02$ & $7.14 \pm 5.87$ & $7.52 \pm 6.40$ \\
\hline
\end{tabular}

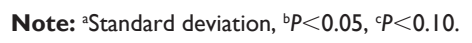




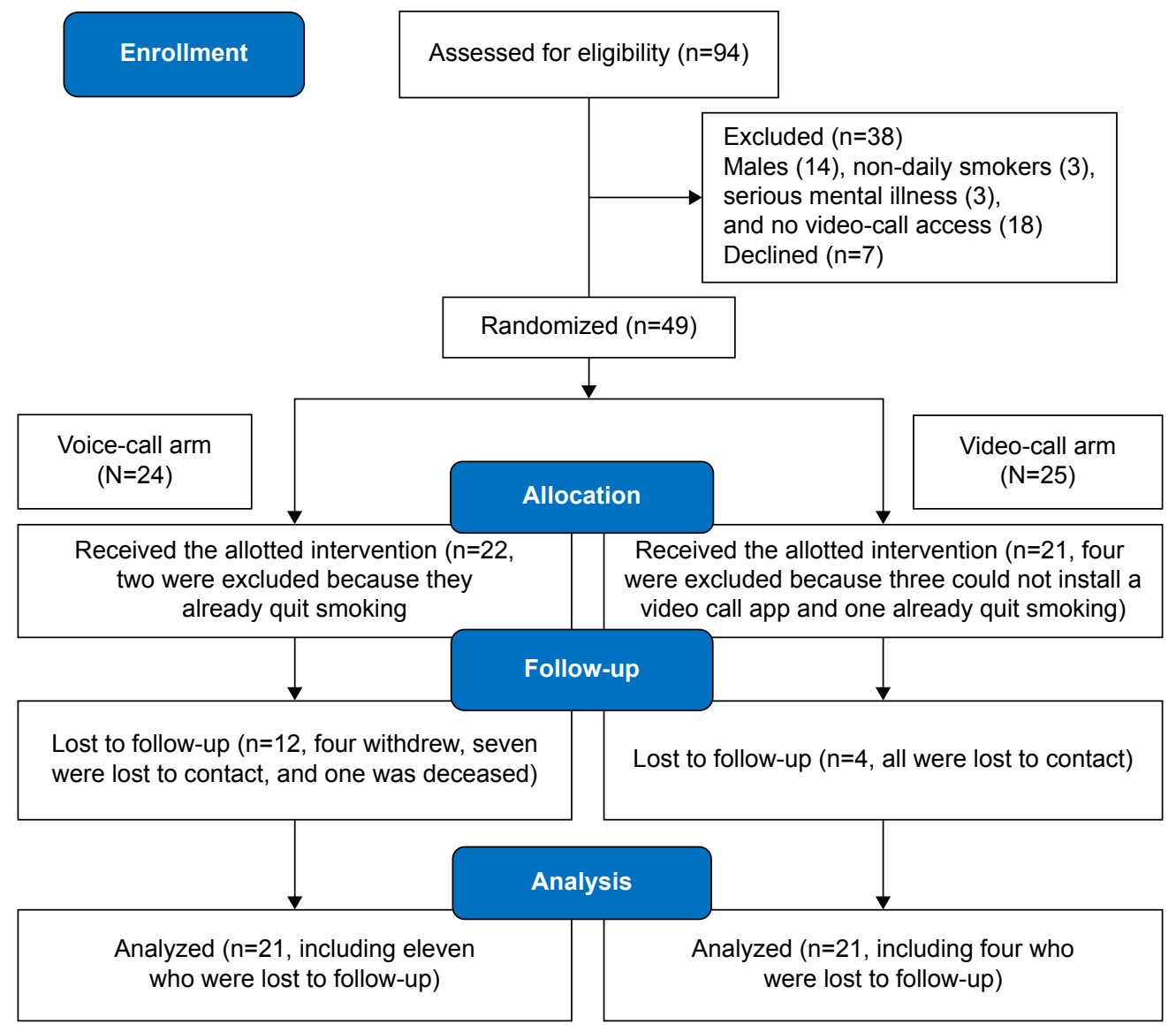

Figure I CONSORT diagram of the study.

reason. Of the 25 women who were randomized into the video, three were excluded before the first counseling session because they could not install a video call app despite multiple attempts with assistance. As a result, feasibility of enrollment in a video-call intervention further decreased to $71.6 \%(53 / 74)$.

\section{Feasibility of intervention delivery}

One in the video arm and two in the voice arm were eliminated during the first counseling session because it was found that they had already quit smoking. Two-thirds of the women in the video arm $(66.7 \%, 14 / 21)$ and $59.1 \%$ in the voice arm $(13 / 22)$ attended all eight counseling sessions, and there was no difference in the feasibility of intervention delivery between the two arms.

\section{Feasibility of retention}

One woman in the voice arm passed away at 3-month follow-up and was excluded from all outcome analyses. The rate of retention till the end point of the study, that was 6-month follow-up from the quit day, was significantly higher $\left(\chi^{2}=5.09, P=0.02\right)$ in the video arm $(17 / 21,81.0 \%)$ than in the voice arm $(10 / 21,47.6 \%)$.

\section{Acceptability}

Fifteen in the video arm and 14 in the voice arm completed the CSQ. The average scores of the questionnaire were almost identical (29.6 vs 28.9) between the video and voice arms. Thus, there was no difference in the acceptability of the two delivery modes, and $\sim 85 \%$ of the women in both arms positively evaluated the intervention.

\section{Smoking abstinence}

At the end of the intervention, $71.4 \%(n=15)$ in the video arm and $52.4 \%(n=11)$ in the voice arm self-reported abstinence, and the rates were not statistically different. Ten $(47.6 \%)$ in the video arm and four (19\%) in the voice arm reported abstinence at 3-month follow-up, but only seven (33.3\%) in the video arm and one $(4.8 \%)$ in the voice arm could be verified with a salivary cotinine test $(P<0.05)$, using the cutoff level of $0(0-10 \mathrm{ng} / \mathrm{mL})$. At 6-month follow-up, one more woman in the video arm who reported smoking at 


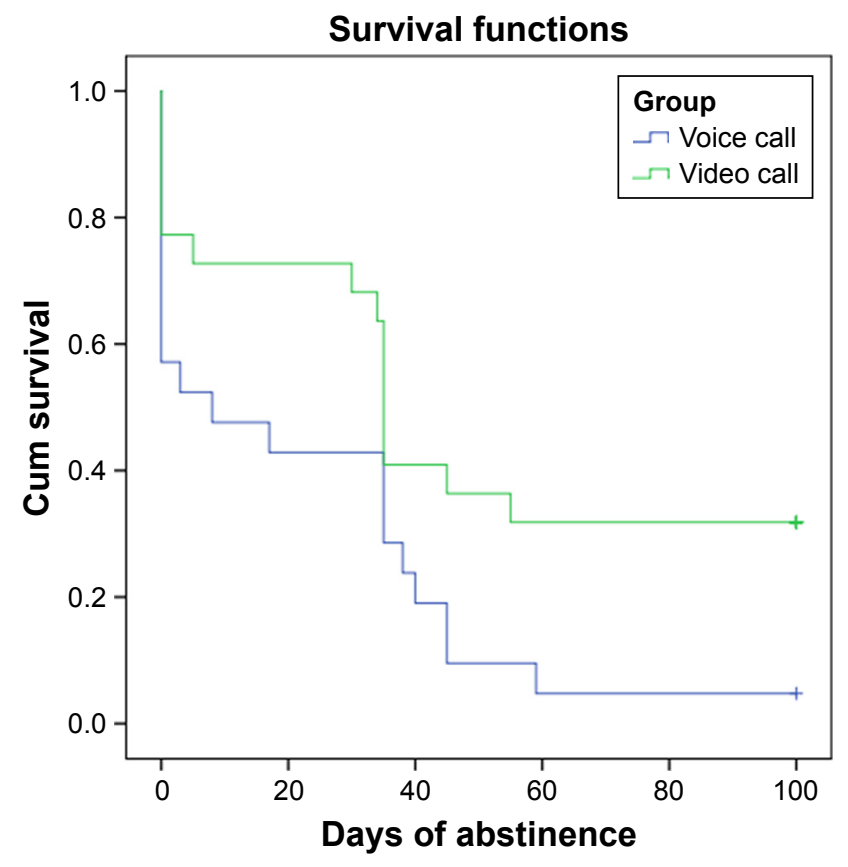

Figure 2 Survival analysis of abstinence in video call group vs the voice call group.

3-month follow-up reported having been abstinent for the past 2 months, and her cotinine test result was 0 . Therefore, the rate of abstinence at the 6-month follow-up was 38.1\% $(8 / 21)$ for the video arm and $4.8 \%(1 / 21)$ for the voice arm $(P<0.05)$. The video-call intervention showed a large treatment effect over the voice-call intervention (the relative risk difference $=0.33$ ). The rate of 6 -month prolonged abstinence was $33.3 \%$ for the video arm and $4.8 \%$ for the voice arm ( $\mathrm{OR}=10.0,95 \% \mathrm{CI}=1.10,90.60, P=0.04)$.

A Kaplan-Meier survival analysis revealed that those in the video arm were significantly more likely to maintain abstinence over the 6-month follow-up period than those in the voice arm ( $\log$ rank $\chi^{2}=4.02, P=0.04$, Figure 2$)$. A Cox proportional hazards model failed to identify a significant predictor of the 6-month prolonged abstinence except for intervention condition (Table 2). Although insignificant, those who had higher levels of nicotine dependence at baseline were less likely to achieve 6-month prolonged abstinence $(P=0.08)$.

\section{Discussion}

To the best of our knowledge, this is the first study of its kind that tested the feasibility and acceptability of an individual-based video-call smoking cessation intervention for US women living with HIV. The video-call intervention was feasible for most women living in east coastal locations, such as New York and Massachusetts. However, its feasibility was questionable for women living in poorer, southern states, such as Alabama. Many women from the region could not participate in the study because they did not own a smartphone or computer. Because of their low socioeconomic status, smoking cessation studies conducted with PLWH have typically provided a prepaid cell phone for telephone counseling or text messaging. ${ }^{71-74}$ The present study did not provide a prepaid cell phone due to limited funds. The geographical disparity in access to video-call equipment is somewhat similar to disparities in HIV treatment and clinical outcomes (eg initiation into combination ART, adherence in HIV medical care, viral suppression, and mortality). ${ }^{75,76}$ It was reported that nine southern states, called the "Deep South" (including Alabama), had a higher HIV diagnosis rate (24.5/100,000 population), than the US overall $(18.0 / 100,000)$ and the highest death rate among PLWH of any US region. ${ }^{77,78}$

Women in their 50 s and 60 s were less likely to use a smartphone than their younger counterparts and some who owned a smartphone did not know how to install a free video call app. This finding is similar to that from our previous study testing the feasibility and acceptability of video-call cessation counseling for smoking cessation in Korean American women. ${ }^{38}$ Another study reported that older adults (aged 50-65 years) showed a lower performance than younger adults (aged 20-35 years) when handling the interface of a mobile phone, placing attention on older age as a potential barrier to smoking cessation interventions using newer technologies. ${ }^{79}$ At the same time, although the feasibility of enrollment was found to be challenging for some, none of the women living with HIV refused or withdrew from the study on the grounds that they did not like doing a video call, suggesting that more

Table 2 Factors predicting 6-month prolonged abstinence

\begin{tabular}{|c|c|c|c|c|c|c|}
\hline \multirow{2}{*}{$\begin{array}{l}\text { 6-month prolonged } \\
\text { abstinence } \\
\text { Intervention condition }\end{array}$} & \multirow{2}{*}{$\begin{array}{l}\text { Coefficient } \\
2.37 \mid 94 I\end{array}$} & \multirow{2}{*}{$\begin{array}{l}\begin{array}{l}\text { Robust } \\
\text { standard error }\end{array} \\
1.183357\end{array}$} & \multirow{2}{*}{$\begin{array}{l}Z \\
2.00\end{array}$} & \multirow{2}{*}{$\begin{array}{l}P>|z| \\
0.045\end{array}$} & \multicolumn{2}{|c|}{$\mathbf{9 5} \%$ confidence interval } \\
\hline & & & & & 0.0526037 & 4.691278 \\
\hline Nicotine dependence & -0.1739063 & 0.1007446 & -1.73 & 0.084 & $-0.37|362|$ & 0.0235495 \\
\hline Constant & $-3 .|7247|$ & 2.393662 & -1.33 & 0.185 & -7.863963 & $|.51902|$ \\
\hline
\end{tabular}


attention to sensitizing women to the use of technology might improve the intervention's feasibility.

Although findings are preliminary because of the nature of a pilot study with a small sample, women who received a smoking cessation intervention via video calls were far more likely to achieve 7-day point prevalence abstinence at 6-month follow-up than their counterparts who received the same intervention via voice calls. Here, the abstinence was verified with a home-based salivary cotinine test that used a NicAlert test strip. The study also found a significant difference in 6-month prolonged smoking abstinence rates between the video and voice arms.

\section{Study limitations}

This was a pilot clinical trial with 42 participants. There was thus insufficient statistical power to achieve generalizability. Additionally, the study results were not generalizable to certain ages or regions since women in their 50 s and $60 \mathrm{~s}$, and those residing in selected southern states could not participate in the study owing to their lack of access to videocall equipment. Approximately, more than one-third of the women in the study were lost to follow-up, primarily from the voice arm (52.4\%), compared to the video arm (19.1\%). The video-call smoking cessation intervention had greater feasibility in terms of retention than the voice-call one, which suggests that video-call counseling might be better in establishing therapeutic alliance than voice-call counseling. Along with a better retention rate, the present study found a large treatment effect of video-call over voice-call counseling. Based on this finding, it would be worthwhile to conduct a large-scale clinical trial to investigate whether the finding would be replicable in larger groups of women living with HIV. If video-call cessation counseling were found to be effective compared with telephone cessation counseling, the intervention modality might pose an ideal alternative to the traditional telephone counseling and could be adopted in a nationwide smoking quit-line service, especially for women living with HIV. In another shortcoming, the study was conducted with volunteers who agreed to have a quit day within 30 days from their first counseling session. Therefore, researchers should be cautious when interpreting findings.

In spite of the limitations stated earlier, the results indicate the feasibility of a video-call smoking cessation intervention for at least $70 \%$ of women living with HIV. Furthermore, the video-call smoking cessation intervention is more likely to retain the women till the end point of the study and more likely to achieve long-term (6 months) smoking abstinence compared to a traditional voice-call smoking cessation intervention. More recently, people of lower socioeconomic status have been offered a low-paying smartphone with a free wireless program (eg, www.SafeLinkWireless.com). ${ }^{80}$ Some women in this study were able to participate owing to this program. Furthermore, the second pilot study underway with women living with HIV revealed that most women in their 50s and 60s now communicate with their grandchildren, using a video-call app. ${ }^{81} \mathrm{~A}$ large scale randomized controlled clinical trial should be conducted to further investigate the efficacy of video-call cessation counseling for women living with HIV compared with voice-call cessation counseling. The video call approach should be investigated for its potential to become a scalable and effective intervention strategy, particularly for women living with HIV who are less likely to quit when assisted with the traditional voicecall counseling.

\section{Acknowledgments}

The study was partially supported by a Joseph P. Healey Research Grant awarded to Drs Kim, Sprague, and DeMarco by the University of Massachusetts (UMass) Boston and the UMass Boston - Dana Farber Harvard Cancer Center U54 Partnership (U54 grant) to Drs Kim and DeMarco. The content of this article is solely the responsibility of the authors and in no way reflects the official policy of the university.

\section{Disclosure}

The authors report no conflicts of interest in this work.

\section{References}

1. Pacek LR, Harrell PT, Martins SS. Cigarette smoking and drug use among a nationally representative sample of HIV-positive individuals. Am J Addict. 2014;23(6):582-590.

2. Palella FJ, Baker RK, Moorman AC, et al; HIV Outpatient Study Investigators. Mortality in the highly antiretroviral therapy era: changing causes of death and disease in the HIB outpatient study. J Acquir Immune Defic Syndr. 2006;43(1):27-34.

3. Lifson AR, Neuhaus J, Arribas JR, et al. Smoking-related health risks among persons with HIV in the Strategies for Management of Antiretroviral Therapy clinical trial. Am J Public Health. 2010;100(10): 1896-1903.

4. Moscou-Jackson G, Commodore-Mensah Y, Farley J, Digiacomo M. Smoking-cessation interventions in people living with HIV infection: a systematic review. J Assoc Nurses AIDS Care. 2014;25(1):32-45.

5. Vidrine DJ, Marks RM, Arduino RC, Gritz ER. Efficacy of cell phone-delivered smoking cessation counseling for persons living with HIV/AIDS: 3-month outcomes. Nicotine Tob Res. 2012;14(1):106-110.

6. Vidrine DJ, Kypriotakis G, Li L, et al. Mediators of a smoking cessation intervention for persons living with HIV/AIDS. Drug Alcohol Depend. 2015;147:76-80.

7. Gritz ER, Danysh HE, Fletcher FE, et al. Long-term outcomes of a cell phone-delivered intervention for smokers living with HIV/AIDS. Clin Res Infect Dis. 2013;57(4):608-615. 
8. Balfour L, Wiebe SA, Cameron WD, et al. An HIV-tailored quitsmoking counselling pilot intervention targeting depressive symptoms plus nicotine replacement therapy. AIDS Care. 2017;29(1):24-31.

9. Humfleet GL, Hall SM, Delucchi KL, Dilley JW. A randomized clinical trial of smoking cessation treatments provided in HIV clinical care settings. Nicotine Tob Res. 2013;15(8):1436-1445.

10. Moadel AB, Bernstein SL, Mermelstein RJ, Arnsten JH, Dolce EH, Shuter J. A randomized controlled trial of a tailored group smoking cessation intervention for HIV-infected smokers. J Acquir Immune Defic Syndr. 2012;61(2):208-215.

11. Stanton CA, Papandonatos GD, Shuter J, et al. Outcomes of a tailored intervention for cigarette smoking cessation among Latinos living with HIV/AIDS. Nicotine Tob Res. 2015;17(8):975-982.

12. Ledgerwood DM, Yskes R. Smoking cessation for people living with HIV/AIDS: a literature review and synthesis. Nicotine Tob Res. 2016;18(12):2177-2184.

13. Hessol NA, Weber KM, D'Souza G, et al. Smoking cessation and recidivism in the Women's Interagency Human Immunodeficiency Virus Study. Am J Prev Med. 2014;47(1):53-69.

14. Allen AM, Scheuermann TS, Nollen N, Hatsukami D, Ahluwalia JS. Gender differences in smoking behavior and dependence motives among daily and nondaily smokers. Nicotine Tob Res. 2016;18(6): 1408-1413.

15. Wetter DW, Kenford SL, Smith SS, Fiore MC, Jorenby DE, Baker TB. Gender differences in smoking cessation. J Consult Clin Psychol. 1999; 67(4):555-562.

16. Bohadana A, Nilsson F, Rasmussen T, Martinet Y. Gender differences in quit rates following smoking cessation with combination nicotine therapy: influence of baseline smoking behavior. Nicotine Tob Res. 2003; 5(1):111-116.

17. LeventhalAM,Waters AJ,BoydS,MoolchanET,LermanC,PickworthWB. Gender differences in acute tobacco withdrawal: effects on subjective, cognitive, and physiological measures. Exp Clin Psychopharmacol. 2007; 15(1):21-36.

18. Mckee SA, O’Malley SS, Salovey P, Krishnan-Sarin S, Mazure CM. Perceived risks and benefits of smoking cessation: gender-specific predictors of motivation and treatment outcome. Addict Behav. 2005; 30(3):423-435.

19. Perkins KA, Scott J. Sex differences in long-term smoking cessation rates due to nicotine patch. Nicotine Tob Res. 2008;10(7):1245-1250.

20. Smith PH, Kasza KA, Hyland A, et al. Gender differences in medication use and cigarette smoking cessation: results from the International Tobacco Control Four Country Survey. Nicotine Tob Res. 2015;17(4): 463-472.

21. Xu J, Azizian A, Monterosso J, et al. Gender effects on mood and cigarette craving during early abstinence and resumption of smoking. Nicotine Tob Res. 2008;10(11):1653-1661.

22. Weinberger AH, Pilver CE, Desai RA, Mazure CM, McKee SA. The relationship of major depressive disorder and gender to changes in smoking for current and former smokers: longitudinal evaluation in the US population. Addiction. 2012;107(10):1847-1856.

23. Cepeda-Benito A, Reynoso JT, Erath S. Meta-analysis of the efficacy of nicotine replacement therapy for smoking cessation: differences between men and women. J Consult Clin Psychol. 2004;72(4):712-722.

24. U.S. Department of Health and Human Services (DHHS), Health Resources and Services Administration. A Guide to the Clinical Care of Women with HIV - 2013. Rockville, MA: U.S. Department of Health and Human Services; 2013.

25. KFF.org. Menlo Park: The Kaiser Family Foundation. Women and HIV/ AIDS in the United States. Available from: https://www.kff.org/hivaids/factsheet/women-and-hivaids-in-the-united-states/. Accessed March 6, 2014.

26. Hordacre B. The role of Telehealth to assist in-home tDCS: opportunities, promising results and acceptability. Brain Sci. 2018;8(6):E102.

27. Rasekaba TM, Furler J, Young D, et al. Using technology to support care in gestational diabetes mellitus: quantitative outcomes of an exploratory randomised control trial of adjunct telemedicine for gestational diabetes mellitus (TeleGDM). Diabetes Res Clin Pract. 2018;142: 276-285.
28. Adams N, Hamilton N, Nelson EL, Smith CE. Using telemedicine to identify Depressive Symptomatology Rating Scale in a home parenteral nutrition population. J Technol Behav Sci. 2017;2(3-4): 129-139.

29. Johnson KE, Alencar MK, Coakley KE, et al. Telemedicine-based health coaching is effective for inducing weight loss and improving metabolic markers. Telemed J E Health. Epub 2018 May 30.

30. Harvey JB, Valenta S, Simpson K, Lyles M, McElligott J. Utilization of outpatient Telehealth services in parity and nonparity states 2010-2015. Telemed J E Health. Epub 2018 May 30.

31. Zilliacus E, Meiser B, Lobb E, Dudding TE, Barlow-Stewart K, Tucker K. The virtual consultation: practitioners' experiences of genetic counseling by videoconferencing in Australia. Telemed J E Health. 2010; 16(3):350-357.

32. Moreno FA, Chong J, Dumbauld J, Humke M, Byreddy S. Use of standard Webcam and Internet equipment for telepsychiatry treatment of depression among underserved Hispanics. Psychiatr Serv. 2012; 63(12):1213-1217.

33. Verhoeven F, Tanja-Dijkstra K, Nijland N, Eysenbach G, van GemertPijnen L. Asynchronous and synchronous teleconsultation for diabetes care: a systematic literature review. J Diabetes Sci Technol. 2010;4(3): 666-684.

34. Kitamura C, Zurawel-Balaura L, Wong RK. How effective is video consultation in clinical oncology? A systematic review. Curr Oncol. 2010; 17(3):17-27.

35. Carlson LE, Lounsberry JJ, Maciejewski O, Wright K, Collacutt V, Taenzer P. Telehealth-delivered group smoking cessation for rural and urban participants: feasibility and cessation rates. Addict Behav. 2012; 37(1):108-114

36. Jang Y, Chiriboga DA, Molinari V, et al. Telecounseling for the linguistically isolated: a pilot study with older Korean immigrants. Gerontologist. 2014;54(2):290-296.

37. Haskins BL, Lesperance D, Gibbons P, Boudreaux ED. A systematic review of smartphone applications for smoking cessation. Transl Behav Med. 2017;7(2):292-299.

38. Kim SS, Sitthisongkram S, Bernstein K, Fang H, Choi WS, Ziedonis D. A randomized controlled trial of a videoconferencing smoking cessation intervention for Korean American women: preliminary findings. Int $J$ Womens Health. 2016;8:453-462.

39. Richter KP, Shireman TI, Ellerbeck EF, et al. Comparative and cost effectiveness of telemedicine versus telephone counseling for smoking cessation. J Med Internet Res. 2015;17(5):e113.

40. Marhefka SL, Turner D, Lockhart E, Rivara A, Wang W, Shuter J. Meeting our patients "Where They Are": video-group smoking cessation for people living with HIV. J Assoc Nurses AIDS Care. 2018;29(2): 338-344.

41. Babor TF, Higgins-Biddle JC, Saunders JB, Monteiro MG. The Alcohol Use Disorders Identification Test: Guidelines for Use in Primary Care. 2nd ed. Geneva: World Health Organization; 2001.

42. Bandura A. Social Foundations of Thought and Action: A Social Cognitive Theory. Englewood Cliffs, NJ: Prentice-Hall, Inc; 1986.

43. Fiore M, Jaen CR, Baker T, et al. Treating Tobacco Use and Dependence: 2008 Update. Rockville, MD: US Department of Health and Human Services; 2008.

44. Friis-Møller N, Sabin CA, Weber R, et al. Data Collection on Adverse Events of Anti-HIV Drugs (DAD) Study Group. Combination antiretroviral therapy and the risk of myocardial infarction. $N$ Engl J Med. 2003; 349(21):1993-2003.

45. Kim S, Darwish S, Lee S, Demarco RF. A pilot study of a smoking cessation intervention for women living with HIV: study protocol. Open Access J Clin Trial. 2017;9:11-20.

46. Fiore MC, Jaén C, Baker T. Treating Tobacco Use and Dependence: 2008 Update. Clinical Practice Guideline. Rockville, MD: U.S. Department of Health and Human Services, Public Health Service; 2008:106-128.

47. Larsen DL, Attkisson CC, Hargreaves WA, Nguyen TD. Assessment of client/patient satisfaction: development of a general scale. Eval Program Plann. 1979;2(3):197-207. 
48. Hughes JR, Keely JP, Niaura RS, Ossip-Klein DJ, Richmond RL, Swan GE. Measures of abstinence in clinical trials: issues and recommendations. Nicotine Tob Res. 2003;5(1):13-25.

49. Benowitz NL, Jacob P. Metabolism of nicotine to cotinine studied by a dual stable isotope method. Clin Pharmacol Ther. 1994;56(5): 483-493.

50. Berger BE, Ferrans CE, Lashley FR. Measuring stigma in people with HIV: psychometric assessment of the HIV stigma scale. Res Nurs Health. 2001;24(6):518-529.

51. Grov C, Golub SA, Parsons JT, Brennan M, Karpiak SE. Loneliness and HIV-related stigma explain depression among older HIV-positive adults. AIDS Care. 2010;22(5):630-639.

52. Heatherton TF, Kozlowski LT, Frecker RC, Fagerström KO. The Fagerström Test for Nicotine Dependence: a revision of the Fagerström Tolerance Questionnaire. Br J Addict. 1991;86(9):1119-1127.

53. de Meneses-Gaya C, Zuardi AW, de Azevedo Marques JM, Souza RM, Loureiro SR, Crippa JA. Psychometric qualities of the Brazilian versions of the Fagerström Test for Nicotine Dependence and the Heaviness of Smoking Index. Nicotine Tob Res. 2009;11(10):1160-1165.

54. Huang CL, Lin HH, Wang HH. The psychometric properties of the Chinese version of the Fagerstrom Test for Nicotine Dependence. Addict Behav. 2006;31(12):2324-2327.

55. Kim SS, Fang H, Difranza J, Ziedonis DM, Ma GX, Gx M. Gender differences in the Fagerström Test for Nicotine Dependence in Korean Americans. J Smok Cessat. 2012;7(1):1-6.

56. Wellman RJ, Savageau JA, Godiwala S, et al. A comparison of the Hooked on Nicotine Checklist and the Fagerström Test for Nicotine Dependence in adult smokers. Nicotine Tob Res. 2006;8(4):575-580.

57. Jhanjee S, Sethi H. The Fagerström test for nicotine dependence in an Indian sample of daily smokers with poly drug use. Nicotine Tob Res. 2010;12(11):1162-1166.

58. Radzius A, Gallo JJ, Epstein DH, et al. A factor analysis of the Fagerström Test for Nicotine Dependence (FTND). Nicotine Tob Res. 2003; 5(2):255-260.

59. Yamada H, Acton GS, Tsoh JY. Differential item functioning of the English and Chinese versions of the Fagerstrom Test for Nicotine Dependence. Addict Behav. 2009;34(2):125-133.

60. Raykov T. Scale reliability, Cronbach's coefficient alpha, and violations of essential tau-equivalence with fixed congeneric components. Multivariate Behav Res. 1997;32(4):329-353.

61. Velicer WF, Diclemente CC, Rossi JS, Prochaska JO. Relapse situations and self-efficacy: an integrative model. Addict Behav. 1990; 15(3):271-283.

62. Hu SC, Lanese RR. The applicability of the theory of planned behavior to the intention to quit smoking across workplaces in southern Taiwan. Addict Behav. 1998;23(2):225-237.

63. Radloff LS. The CES-D scale a self-report depression scale for research in the general population. Appl Psychol Meas. 1977;1(3):385-401.

64. Xu J, Azizian A, Monterosso J, et al. Gender effects on mood and cigarette craving during early abstinence and resumption of smoking. Nicotine Tob Res. 2008;10(11):1653-1661.

65. Natamba BK, Achan J, Arbach A, et al. Reliability and validity of the center for epidemiologic studies-depression scale in screening for depression among HIV-infected and -uninfected pregnant women attending antenatal services in northern Uganda: a cross-sectional study. BMC Psychiatry. 2014;14(14):303.
66. Cosco TD, Prina M, Stubbs B, Wu YT. Reliability and validity of the Center for Epidemiologic Studies Depression Scale in a populationbased cohort of middle-aged U.S. adults. J Nurs Meas. 2017;25(3): 476-485.

67. Spitzer RL, Kroenke K, Williams JB, Löwe B. A brief measure for assessing generalized anxiety disorder: the GAD-7. Arch Intern Med. 2006;166(10):1092-1097.

68. Hughes JR, Hatsukami D. Signs and symptoms of tobacco withdrawal. Arch Gen Psychiatry. 1986;43(3):289-294.

69. Etter JF, Hughes JR. A comparison of the psychometric properties of three cigarette withdrawal scales. Addiction. 2006;101(3):362-372.

70. Hertzog MA. Considerations in determining sample size for pilot studies. Res Nurs Health. 2008;31(2):180-191.

71. Vidrine DJ, Marks RM, Arduino RC, Gritz ER. Efficacy of cell phonedelivered smoking cessation counseling for persons living with HIV/ AIDS: 3-month outcomes. Nicotine Tob Res. 2012;14(1):106-110.

72. Vidrine DJ, Kypriotakis G, Li L, et al. Mediators of a smoking cessation intervention for persons living with HIV/AIDS. Drug Alcohol Depend. 2015;147:76-80.

73. Gritz ER, Danysh HE, Fletcher FE, et al. Long-term outcomes of a cell phone-delivered intervention for smokers living with HIV/AIDS. Clin Infect Dis. 2013;57(4):608-615.

74. Tseng TY, Krebs P, Schoenthaler A, et al. Combining text messaging and telephone counseling to increase varenicline adherence and smoking abstinence among cigarette smokers living with HIV: a randomized controlled study. AIDS Behav. 2017;21(7):1964-1974.

75. Althoff KN, Rebeiro P, Brooks JT, et al. Disparities in the quality of HIV care when using US Department of Health and Human Services indicators. Clin Infect Dis. 2014;58(8):1185-1189.

76. Valdiserri RO, Forsyth AD, Yakovchenko V, Koh HK. Measuring what matters: development of standard HIV core indicators across the U.S. Department of Health and Human Services. Public Health Rep. 2013;128(5):354-359.

77. Reif S, Pence BW, Hall I, Hu X, Whetten K, Wilson E. HIV diagnoses, prevalence and outcomes in nine southern states. J Community Health. 2015;40(4):642-651.

78. Reif S, Safley D, McAllaster C, Wilson E, Whetten K. State of HIV in the US Deep South. J Community Health. 2017;42(5):844-853.

79. Ziefle M, Bay S. How older adults meet complexity: aging effects on the usability of different mobile phones. Behav Inf Technol. 2005;24(5): 375-389.

80. SafeLink Wireless. Free Wireless Program Live Connected. Available from: https://www.safelinkwireless.com/Enrollment/Safelink/en/Web/ www/default/index.html\#!/newHome. Accessed April 13, 2018.

81. U.S. National Library of Medicine. ClinicalTrials.gov. Storytelling narrative communication intervention for smoking cessation in women living with HIV (WISE). Available from: https://clinicaltrials.gov/ct2/ show/NCT03289676. Accessed August 30, 2018.
International Journal of Women's Health

\section{Publish your work in this journal}

The International Journal of Women's Health is an international, peerreviewed open-access journal publishing original research, reports, editorials, reviews and commentaries on all aspects of women's healthcare including gynecology, obstetrics, and breast cancer. The manuscript management system is completely online and includes

\section{Dovepress}

a very quick and fair peer-review system, which is all easy to use. Visit http://www.dovepress.com/testimonials.php to read real quotes from published authors. 